\title{
Evaluation of Noise pollution in the schools of Birjand city and its administrative solutions, in 2011
}

\author{
Sayadi MH, $\mathrm{PhD}^{1}$, Movafagh A, MSc ${ }^{2 *}$, Kargar R, MSc ${ }^{3}$, Movafagh Kh, BSc ${ }^{4}$
}

1- Assistant Prof., Dept. of Environmental Sciences, Natural Resource and Environment School, University of Birjand, Birjand, Iran. 2- Student of Environments and Energy School, Islamic Azad University of Tehran, Tehran, Iran. 3- Student, Dept. of Civil Engineering, Engineering School, University of Birjand, Birjand, Iran.4- Teacher, Dept. of Education, District 4 of Tehran, Tehran, Iran.

\begin{abstract}
Received: April 2013, Accepted: December 2013

Background: Educational centers have higher standards for controlling noise pollution as it has been shown that noise pollution is a major cause of discomfort for teachers and students. Noise pollution reduces concentration, interferes in the conversation, and leads to dropouts and lower grades especially in mathematics. The present study aimed to evaluate noise pollution in the schools of Birjand and its administrative solutions in 2011.

Materials and Methods: This study examined the level of noise pollution in the schools of Birjand city and suggested implementation to reduce noise pollution. The Casellacel model Cel450 was used in accordance with international standards. Through exhaustive field visits and interviews with school authorities; 12 schools (4 each from primary, middle and high schools) were randomly selected in the different parts of the city.

Results: The results showed that the schools under study were badly affected by noise pollution, as these noise levels were higher than the standard levels $(35 \mathrm{~dB})$. The maximum noise level during class time was recorded as $72.3 \mathrm{~dB}$, while the maximum noise level during recess time was recorded as $87.4 \mathrm{~dB}$. Ineluctably, the schools with high student/class ratio showed a higher noise pollution level.

Conclusion: It can be concluded that, the schools in different regions of Birjand have problems in terms of noise pollution. Fortunately, all school authorities were aware of this issue and with all facilities and special arrangements tried to resolve the problem. However, the major factors responsible for the noise pollution were out of their control.
\end{abstract}

Key Words: Schools, Noise Pollution, Educational

\section{Introduction}

In the age of technology, noise pollution is recognized as the most common cause of acquired hearing loss. When the hearing is hurt, it is not treatable. Unfortunately, patients become aware of their disease when it reaches an acute stage and is irreversible (1). Many of the damages of bustle and noise pollutions are the biological stressors, irritations and damages to the nervous systems and devastating effects on the auditory system and the mind $(2,3)$. Most people have gradually become accustomed to their surrounding noises. This may be due to the simple reason that not only noise pollution has compelled masses to know it as an inherent part of life but also accustomed them to its discomforts. Ultimately, a hormonal disorder and consequent hearing

\footnotetext{
* Corresponding author: Afsaneh Movafagh, Student of Environments and Energy School, Islamic Azad University of Tehran, Tehran, Iran.

Email: Afsaneh_movafagh@yahoo.com
} 
loss are hallmarks of its objectives. Moreover, its after-effects are a patient's inability to communicate effectively and efficiently with the surrounding community, thus reducing the quality of life besides mental and emotional health $(4,5)$.

School and classroom noise (scraping sounds from tables and chairs) hinder concentration of students at schools (6). People's talking, singing and even their expressions of short words and crosswords hurt IQ of an individual. It as well weakens a student's ability to write, read, understand and solve mathematical problems and learn vocabularies. So, it is an effective step to keep the place quiet and calm whenever a student is learning or doing his or her homework (7).

Bronzaft and McCarthy (1975) found significant differences in reading scores of primary school children studying in a quiet classroom as compared to those nestled in the classroom with high levels of railway noise (8). Optimal acoustics in classrooms prevents students to clearly listen to the teacher's speech. Inevitably, in the classes devoid of carpets, and curtains but consisting wooden or metal chairs, noise remains for a longer period of time. In addition, such classes are packed with chattering voices, paper rustles and the collision of pencils with chairs thus compelling a teacher to speak very loud which is consequently inappropriate for students. Although when teachers speak loud, most of the students hear the voice clearly; but under these conditions their concentrations and abilities are hampered (9, $10)$.

The aim of the present study was to examine the level of noise pollution in the selected schools of Birjand city and subsequently implement efficacious strategies to reduce noise pollution, which has a significant impact on health and learning of the students.

\section{Materials and Methods}

This descriptive study evaluated the level of noise pollution in the selected schools of Birjand city in 2011. This research examined the efficiency of students in the selected primary, middle and high schools of Birjand city. In this study, the Casellacel "sound meter" model Cel-450 was used which is in accordance with international standards (11). In order to get the permission from the Department of Education of Birjand city; the necessary information was collected from primary, middle and high schools. Simultaneously, through field visits and interviews with school, authorities and considering the geographical locations, the city was divided into 4 districts. Then, among 177 schools in Birjand city, 12 schools (4 each from primary, middle and high schools) were randomly selected. It should be noted that stability was achieved between sex ratios and the number of schools. The sound meter device was installed in the school buildings at their entrance halls. Then an analysis was conducted considering the level of equivalent sound pressure during class time and recess time. Leq index was used to determine the average noise levels.

Equivalent Noise Level Leq:

Equivalent noise level is the average noise level changes in a specified period of time. This time can be considered a second up to twenty-four hours but in the instruction set it is 30 minutes. Equivalent noise level is obtained from the following equation (12).

$$
L_{e q}=10 \log \left(\frac{1}{T} \int_{0}^{T} \frac{P^{2}(t)}{P_{0}^{2}} d t\right)
$$


Where:

T: Time measured in seconds

$\mathrm{P}(\mathrm{t})$ : Sound pressure moment on the square in Newton

P0: Reference sound pressure, equal to $(2 \times$ 10-5) N/m2

Before each measurement, the accuracy of the sound level meter was ensured and, the accuracy of the measuring device was calibrated with standard tools. Since many factors can affect the accuracy of the noise level meter, the calibration of the device was ensured before each use. Calibration was performed by frequency and relative levels of $1 \mathrm{KHz}$ and $114 \mathrm{~dB}$ respectively (12). The average noise level was measured and the data were stored in the Microsoft excel software. The descriptive analysis and regression correlation was calculated using SPSS software and $95 \%$ confidence interval was reported.

\section{Results}

Table 1 shows the characteristics of the schools under study. The average number of students was $327.8 \pm 94$ while the average number of classes was 12.2 \pm 2.6 . The maximum and minimum student/class ratio were 32 and 20.5 respectively, with an average of 26.6 \pm 3.4 .

Analysis of the equivalent sound pressure level (LAeq $30 \mathrm{~min}$ ) during class and recess time in the different school is given in Table 1. It reveals from the results that all schools under study were badly affected by noise, as these noise levels were higher when compared with the standards of the National Building Regulations standard (35 dB). These findings are similar to those reported in other cities of Iran like, Tehran, Karaj, $\operatorname{Ilam}(10,13,14)$.

Table 1: The characteristics of the schools with level of equivalent sound pressure level

\begin{tabular}{|c|c|c|c|c|c|}
\hline School & $\begin{array}{l}\text { Number of } \\
\text { Students }\end{array}$ & $\begin{array}{c}\text { Number of } \\
\text { Classes }\end{array}$ & $\begin{array}{c}\text { ratio } \\
\text { Student/class } \\
\text { ratio }\end{array}$ & $\begin{array}{c}\text { LAeq (30min) in } \\
\text { during } \\
\text { class time }(\mathrm{dB})\end{array}$ & $\begin{array}{l}\text { LAeq (30min) in } \\
\text { during recess time } \\
(\mathrm{dB})\end{array}$ \\
\hline 1 & 205 & 10 & 20.5 & 64.08 & 76.6 \\
\hline 2 & 201 & 9 & 22.3 & 58.8 & 71.67 \\
\hline 3 & 414 & 14 & 29.6 & 72.3 & 84.4 \\
\hline 4 & 480 & 15 & 32.0 & 61.9 & 82.69 \\
\hline 5 & 366 & 12 & 30.5 & 63.8 & 78.88 \\
\hline 6 & 343 & 14 & 24.5 & 61.8 & 81.25 \\
\hline 7 & 200 & 8 & 25.0 & 68.8 & 79.9 \\
\hline 8 & 402 & 15 & 26.8 & 62.3 & 74.6 \\
\hline 9 & 250 & 9 & 27.8 & 65.6 & 79.3 \\
\hline 10 & 324 & 12 & 27.0 & 65.5 & 79.8 \\
\hline 11 & 401 & 14 & 28.6 & 70.7 & 87.4 \\
\hline 12 & 348 & 14 & 24.9 & 68.9 & 85.1 \\
\hline Mean & 327.8 & 12.2 & 26.6 & 65.4 & 80.1 \\
\hline SD & 94.0 & 2.6 & 3.4 & 4.1 & 4.5 \\
\hline Max & 480 & 15 & 32.0 & 72.3 & 87.4 \\
\hline Min & 200 & 8 & 20.5 & 58.8 & 71.7 \\
\hline
\end{tabular}




\section{Discussion}

The monitoring of the schools showed that the maximum noise level during class time was recorded in school number 3, while the maximum noise level during recess time was recorded in school number 11. The result showed that the schools with high student/class ratio had approximately high noise pollution level. It is interesting to note that school number 2 had lowest noise level during class and recess time which is far away from out-of-school noise pollution resources. In general, the noise pollution level during recess time was higher than class time (Table 1).

Similarly, the higher noise level recorded in the hallways during recess time has been reported by many researchers worldwide $(15$, 16).

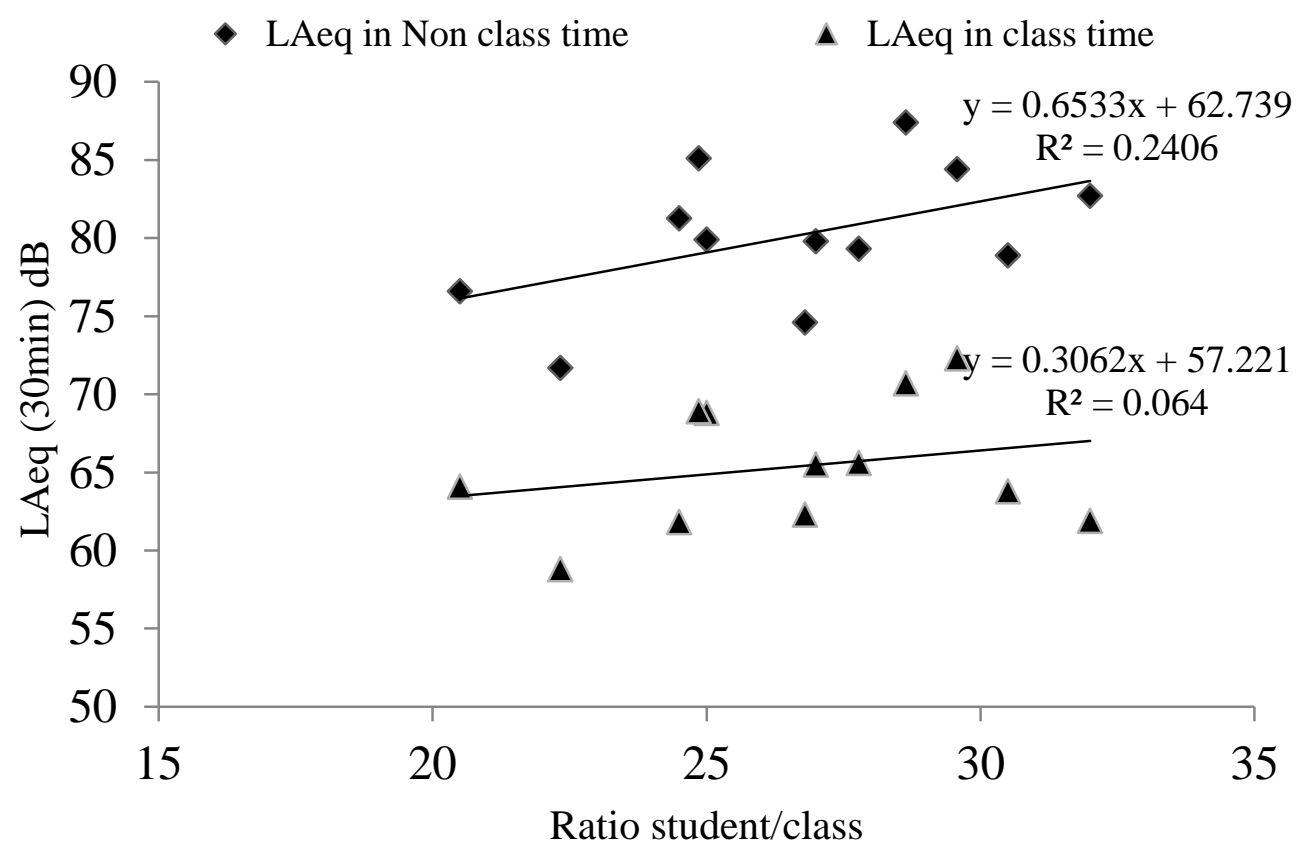

Figure1. The correlation of LAeq (30 min) $\mathrm{dB}$ during class and recess time with student/class ratio

Figure 1 examined the relations between noise exposure at school and student/class ratio and it clearly showed that there is no significant relationship $\left(\mathrm{R}^{2}=0.064\right)$ between LAeq (30min) during class time and student/class ratio, whereas it considerably showed a more significant relationship $\left(\mathrm{R}^{2}=0.24\right)$ during recess time. Therefore, it can be suggested that the main sources of noise pollution in schools are out-of-school sources such as traffic pollution, commercial and residential centers besides school resources like teachers and students' voices in addition to the voices of entertainments and sports. Acoustical properties of structural walls, windows, doors, floors, schools and their internal coverage can appreciably affect the noise pollution level (10). It is important to mentione here that school floors were covered with mosaic and stone. Surprisingly, 
the 20 schools in Saudi Arabia studied for noise level pollution exhibited an Laeq between 60-89.2 $\mathrm{dB}(16)$. Undoubtedly, the noise levels of schools near streets and crowded urban areas were higher. It can be suggested here that the type of window and acoustical properties of structural walls, and doors in addition to school building acoustics are responsible for noise pollution (10).

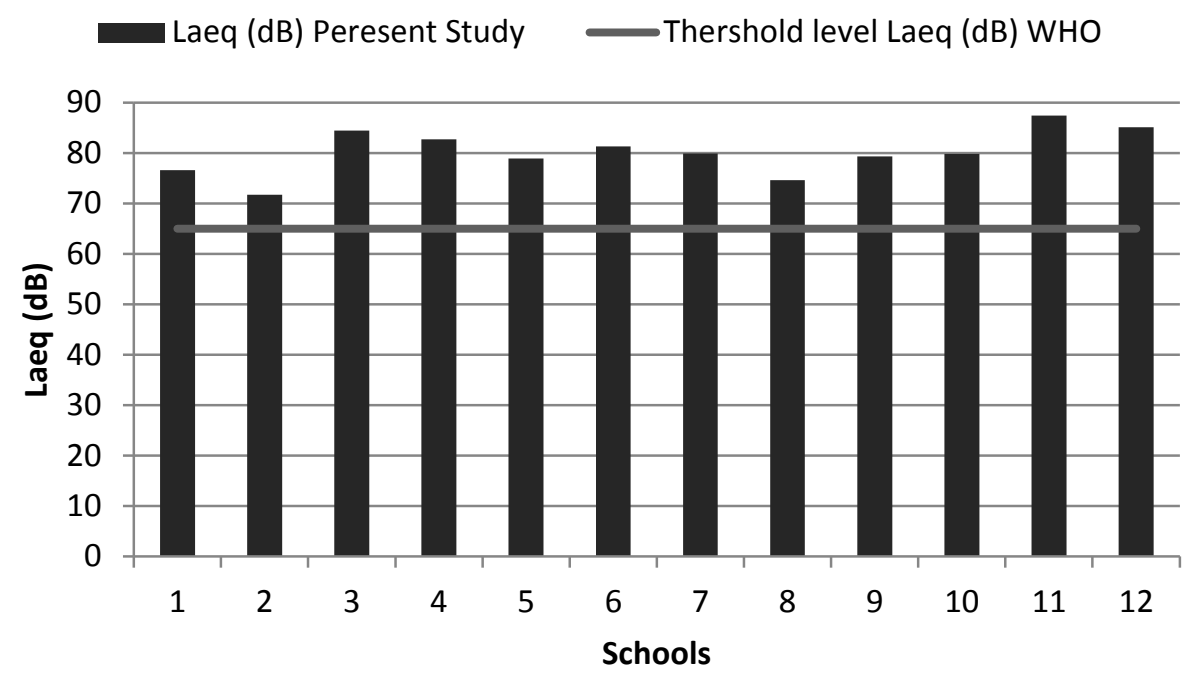

Figure 2 Average noise pollution level in Teaching hours and threshold level of WHO

As shown in Figure 2 the noise pollution level in all the schools were above the threshold limit values $(65 \mathrm{~dB})$ as suggested by the World Health Organization (1997) to prevent interference with speech and sound effects (17).

As far as the higher noise pollution levels in relation to threshold limits are concerned, it can be safely mentioned that the students in the selected Birjand city schools suffer from noise pollution which in turn affects their reading comprehension and concentrations in the classrooms. The reading comprehension could be referred as children's reading ability skills, for example attention, episodic memory and working memory (18). The results from other researches demonstrated that the schools with high levels of noise pollution are generally deprived, and children from the similar high social deprivation schools depict poor performance on reading comprehension tasks, leading to potential confounding (6).

Recommendations for reducing or eliminating noise pollution in schools are explained as follows:

- Transition of schools up to the levels that are standardized in terms of noise pollution.

- Transition of commercial and industrial centers away from school.

- Utilization of acoustic noise barriers such as walls, green spaces between schools and noise pollution sources.

- Provision of the soundproof doors and insulated windows and doors for classes.

- Shutting the class doors during the teaching period. 
- Separate placement of land sports, school workshops and laboratories from classrooms.

- Conducting elaborative studies in the future to locate noise pollution reduction ways in schools.

\section{Conclusion}

In the present study we can conclusively suggest that excessive noise persecutes everyone, especially school students and teachers. Generally, educational centers often have higher standards to control noise pollution but this study satisfactorily evaluated that the noise pollution is a major cause of discomfort for the teachers and students. Therefore, the present study safely concludes that the schools in different regions of Birjand have problems in terms of noise pollution. Fortunately, all school authorities were aware of this issue and with all facilities and special arrangements had tried to resolve the debilitating. Problem nevertheless, the major factor responsible for the noise pollution is out of their control.

\section{Acknowledgment}

The authors would like to appreciate the Department of Environment, Head Office, South Khorasan and University of Birjand authorities for their cooperation and support. Special thanks to the school authorities who helped. We also like to thank Dr. Mrs. Mahavash F. Kavian for editing the paper.

Conflict of interest: Non declared

\section{References}

1. Caciari T, Rosati MV, Casale T, Loreti B, Sancini A, Riservato R, et al. Noise-induced hearing loss in workers exposed to urban stressors. Sci Total Environ 2013; 463464:302-8.

2. Kasimonje BM. Impact of aircraft noise and language on primary school learners' reading comprehension in KwaZulu-Natal [MSc Thesis]. Johannesburg: University of Witwatersrand; 2013.

3. Franssen EAM, Staatsen BAM, Lebret E. Assessing health consequences in an environmental impact assessment: The case of Amsterdam Airport Schiphol. Environ Impact Assess Rev 2002; 22(6):633-53.

4. Stansfeld SA, Matheson MP. Noise pollution: Non-auditory effects on health. Br Med Bull 2003; 68:243-57.

5. van Kempen E, Fischer P, Janssen N, Houthuijs D, van Kamp I, Stansfeld S, et al. Neurobehavioral effects of exposure to traffic-related air pollution and transportation noise in primary school children. Environ Res 2012; 115:18-25.

6. Ali SAA. Study effects of school noise on learning achievement and annoyance in Assiut city, Egypt. Applied Acoustics 2013; 74(4):602-6.

7. Haines MM, Stansfeld SA, Brentnall S, Head J, Berry B, Jiggins $M$, et al. The West London Schools Study: The effects of chronic aircraft noise exposure on child health. Psychol Med 2001; 31(8):1385-96.

8. Bronzaft AL, McCarthy DP. The effects of elevated train noise on reading ability. Environ Behav 1975; 7(4):517-28.

9. Murthy VK, Majumder AK, Khanal SN, Subedi DP. Assessment of traffic noise pollution in banepa, a semi urban town of Nepal. Kathmandu University Journal of Science, Engineering and Technology 2007; $1(4): 1-9$.

10. Golmohammadi R, Ghorbani F, Mahjoub H, Daneshmehr Z. Study of the noise pollution indices and acoustic properties of building schools in Tehran. Journal of Environmental Science and Technology 2011; 12(1):29-38.

11. Dehqan A, Scherer RC. Objective voice analysis of boys with profound hearing loss. Journal of Voice 2011; 25(2):e61-5.

12. Environment Protection Authority. Protection of the Environment Operations (Noise 
Control). Sydney: Environment Protection Authority (EPA); Regulation 2008.

13. Nasiri P, Abbaspoor M, Mahmoodi M, Babaei A. Assessment of noise pollution in schools of the central Division of Karaj city. Journal of Environmental Science and Technology 2006; 7(4):16-29.

14. Nasiri P, Sajadi J. Sound pollution in schools study Eilam and administrative solutions and the clarity of the words Indices. Journal of Environmental Science and Technology 2009; 32(1):215-20.

15. Koszarny Z, Jankowska D. Determination of acoustic climate inside high schools in comparison with elementary schools. Rocz Panstw Zakl Hig 1996; 47(4):423-9.

16. Noweir MH, Ikhwan MA. Study of noise pollution in Jeddah schools. J Egypt Public Health Assoc 1994; 69(3-4):149-62.

17. World Health Organization 1980. Environmental Health Criteria12: Noise. $2^{\text {nd }}$ ed. Geneva: World Health Organization. P42.

18. Clark C, Martin R, Van Kempen E, Alfred T, Head J, Davies HW, et al. Exposure-effect relations between aircraft and road traffic noise exposure at school and reading comprehension: The RANCH project. Am J Epidemiol 2006; 163(1):27-37. 